\title{
Sociologia da inovação técnica: da crítica à técnica ao design sócio-técnico
}

Franz Josef Brüseke ${ }^{1}$

Resumo

O fato que a força motriz inovadora dos tempos modernos foi identificada com a racionalização dificulta até hoje uma interpretação exclusivamente positiva do conceito de inovação. Mas é possível pensar na técnica e seu futuro sem se render a uma crítica abstrata, fornecida pelo discurso ético? Ou sem se deixar levar por uma requentada filosofia do progresso, com a inovação tecnológica no seu centro? Neste momento não surpreende mais, tanto que o conceito de design começa substituir, para alguns autores, os antigos conceitos de modernização ou até de revolução. Nessa perspectiva até o conceito de inovação pode ser substituído pelo conceito do design, com a vantagem de fornecer critérios diferenciados do seu uso. Revisitar, e seja isto somente enquanto exercício da nossa imaginação como inventores e inovadores, aquilo que existia enquanto techné antes dos tempos modernos, pode eventualmente dar pistas para um redesign do dispositivo técnico contemporâneo. Redescobrir o momento estético da antiga técnica diminui, porventura, a terrível tensão entre as inovações tecnológicas e as exigências éticas contemporâneas.

Palavras Chave: Sociologia da técnica, inovacao, design sócio-técnico 


\title{
Sociology of technical innovation: from the critic of technique to socio technical design
}

\begin{abstract}
An interpretation about innovation's concept exclusively positive is difficulted by the fact that driving force of the modern times was identified as the same time as rationalization. But is it possible to think about technique and its future without surrender by abstract critics provided by ethical speech? Or even without being taken by a served-up philosophy of the progress with technological innovation on its bottom? By this time it's not a surprise that the concept of design begins to replace the oldest concepts of modernization or even revolution. At this perspective even the concept of innovation can be replaced by design's concept, with an advantage of providing many differential critereas about its use. Revisiting, as just as an imagination's exercise of ours as inventors and groundbrakers, what already had existed as techné before modern times, can eventually reveal trails to a redesign of contemporary and technical displays. Rediscover the aesthetic moment eventually reduces the terrible tension between technology innovation and contemporany ethical demands.
\end{abstract}

Keywords: Sociology of Technique, Innovation, Sociological-technical Design

Do ponto de vista sociológico ou, em geral, das ciências humanas uma aproximação ao conceito de inovação parece à primeira vista um empreendimento difícil. Estrito senso não existe nenhuma definição clara deste conceito e aparentemente nenhuma das ciências humanas sente-se responsável por ele. Desta maneira a sociologia prefere analisar processos sociais em transformação e denomina-os de mudança social; para ela o conceito de inova- 
ção parece ter uma conotação normativa que a ciência sociológica deve evitar. Consequentemente, com os sociólogos parece mais fácil dialogar sobre a "revolução" do que sobre a "inovação", que para muitos parece ter um compromisso com a manutenção dos parâmetros básicos (e sejam estes altamente dinâmicos) do "capitalismo". 0 discurso sociológico conhece a "ruptura de uma estrutura", a "reforma", o "processo", o "desenvolvimento," a "evolução" e outros conceitos desta natureza, como a "dinâmica social," que indicam uma concepção histórica e processual do fenômeno social. Mas a inovação?

Na verdade, as ciências sociais possuem desde cedo, se usamos este termo suficientemente abrangente, um conceito de inovação embutido e absorvido pelo conceito central de qualquer teoria sobre a modernidade e a modernização, i.e. o conceito de racionalização.

A interpretação da sociedade moderna como produto da racionalização acompanha a sociologia desde os seus primórdios, não obstante, apontaram autores de renome para efeitos não intencionados do próprio processo da racionalização. Assim ela restringiria o bem-estar psicológico (Freud, 1963), levaria à construção de uma gigantesca gaiola de ferro (Weber, 1991), aumentaria a suscetibilidade da sociedade e da economia por crises (Durkheim, 1984 e Marx, 1972) ou alienaria o homem de uma vida verdadeira e autêntica (Adorno/Horkheimer 1971; Horkheimer, 1937; Heidegger, 1927). As interpretações críticas do processo de racionalização ganharam força em consequência de experiências negativas com certos aspectos do desenvolvimento tecnológico e da modernidade como tal, o que fortaleceu argumentos que apontavam a irracionalidade dos tempos modernos em detrimento da sua racionalização crescente (Brüseke, 1991, 1996). Não por último, radicalizou a crítica pós-moderna as duvidas referentes à racionalidade da modernidade, crítica que se empenhou para denunciar a própria razão iluminista (Lyotard, 1979; Sloterdijk, 1983; Bauman, 1991; Maffesoli, 2001). 
Já em Karl Marx encontramos uma teoria da racionalização econômica, que no fundo se resume economicamente a uma única dinâmica, todavia fundamental para a força inovadora da empresa moderna. Marx vai nos dizer que no processo da produção capitalista está sendo gasto intencionalmente cada vez menos trabalho por unidade de produto. Inovação racionalizante significa, nesta perspectiva, economizar tempo de trabalho. A consequente massificação da produção é resultado disso e impensável sem uma inovação tecnológica permanente. 0 capital constante, que representa para Marx todos os insumos com exceção da massa salarial, absorve de certa maneira a dinâmica da racionalização econômica, sem ser todavia, a fonte do lucro empresarial. Seguindo a teoria de valor trabalho de Ricardo, Marx revela o trabalho humano, o capital variável, como fonte de uma assim chamada mais-valia absoluta ou relativa. Nesta perspectiva, a busca da mais-valia relativa impulsiona a racionalização da produção. Identificar o trabalho como única fonte de valor parece hoje uma teoria um tanto uni-dimensional, ainda mais quando vinculado com uma teoria de exploração e crescente miséria do proletariado industrial. Não obstante, um olhar sobre a prática empresarial confirma: sem uma inovação organizacional e tecnológica, sem um rearranjo permanente de todos os fatores de produção, com uma palavra, sem uma modernização contínua, a empresa singular está fadada ao fracasso. Reconhecer o mérito de Karl Marx no campo da formulação de uma teoria econômica de racionalização, contida no primeiro volume de 0 Capital (Marx, 1858/1972a) não implica, ao nosso ver, na obrigação de aceitar os outros elementos da sua teoria do capitalismo, e muito menos de embarcar na sua filosofia da história, ora determinista, ora de cunho escatológico.

No cerne da teoria econômica de Marx, então, podemos detectar uma teoria da racionalização que faz com que ninguém menos do que Max Weber não tenha nenhum problema em seguir esse caminho, quando formulava sua teoria sociológica da sociedade moderna. Weber, não obstante, vai muito além de uma teoria eco- 
nômica da racionalização. Ele vê racionalização também como intelectualização, como destruição de qualquer pensamento mítico, místico, mágico, afinal como desencantamento do mundo ou, na formulação de Schluchter (1981), como racionalização da dominação do mundo.. Para Weber a racionalização aparece muito antes da racionalização econômica, detectada por Marx, ela tem sua origem na desmagificação do campo religioso. Mais ainda, enquanto racionalização ocidental ela tem suas raízes mais tenras nas racionalizações filosóficas da antiguidade grega. Aspecto que Heidegger, mais tarde, vai explorar e radicalizar nas suas análises da técnica moderna e da metafísica européia, expandindo mais ainda o alcance da teoria da racionalização.

Curiosamente, todas as teorias da racionalização apresentam-na como se ela tivesse uma tendência de continuar sem parar. Marx ainda cumprimenta-a como motor do progresso histórico, vinculado com o inevitável desdobramento das forças produtivas. Weber, no entanto, já vê nela uma força ambígua que restringe ao longo prazo a liberdade humana, aprisionando o homem numa "gaiola de ferro". Heidegger, na sua filosofia da técnica, interpreta a racionalização científica e a técnica como o destino do homem, levando este à beira do abismo do esquecimento do Ser. Apesar das grandes diferenças nas abordagens encontramos nestes autores uma compreensão da sociedade contemporânea moldada pela modernização técnica. A modernidade entendida como um processo de mudança histórica essencialmente técnica e racionalizante, apareceu para seus teóricos sob uma luz ambígua. Podemos verificar em praticamente todos os autores que já se debruçaram sobre essa dinâmica inovadora uma certa preocupação se não uma crítica direta.

Sem dúvida, captam as teorias da racionalização a essência dos tempos modernos e nos revelam o porquê da sua inegável habilidade de se impor enquanto dinâmica globalizante. Não obstante, o "espírito do capitalismo" desaparece frequentemente atrás de uma nuvem de teorias mais variadas que, de uma ou 
outra forma, tentam entender o que aconteceu no berço do capitalismo e do racionalismo ocidental: a Europa. 0 problema, a nosso ver, começa aqui, pois a visão clara da dinâmica racionalizante começa ficar embaçada quando elementos políticos, culturais e históricos europeus se colocam no caminho do observador. As análises históricas revelam, sim, como alguns países da Europa se transformaram sob impacto da racionalização, mas misturam frequentemente singularidades européias com a essência da modernidade, que é - na nossa leitura - técnica e racionalizante. Assim estão sendo avaliadas as tradições iluministas como aspecto típico ou até essêncial da modernidade, enquanto se trata de um sequência de eventos particularmente europeus, que dizem respeito a um nível normativo ou moral da própria Europa central, em especial da Grã Bretanha, da França e de menor porte, da Alemanha. Na Europa, e somente na Europa, confundem-se de fato inovação técnica e econômica com o iluminismo e suas ambições políticas e morais. Mas na própria Europa começa o processo de enfraquecimento das ondas esclarecedoras, que chegam inicialmente somente tão longe como as tropas napoleônicas e dependem do tempo lento da alfabetização das grandes massas populacionais. A percepção de uma intrínseca, mas ilusória, ligação entre modernização técnica e "modernização" política é, também, uma ilusão primeiramente e tipicamente européia. É até curioso que governos europeus custeiem ainda no século XX projetos desenvolvimentistas de cunho meramente técnico na Ásia e África para se surpreender depois com o fato que uma fábrica de adubos químicos não fortalece as instituições democráticas.

0 fato que a força motriz inovadora dos tempos modernos foi identificada com a racionalização dificulta até hoje que cientistas treinados no campo das ciências sociais e humanas aceitem uma interpretação exclusivamente positiva do conceito de inovação. Nas últimas décadas manifestou-se essa dificuldade na preponderância de críticas e dúvidas, neste campo do conhecimento, quando se tratava de discutir novas tecnologias, como usinas 
nucleares, biotecnologias, nanotecnologias e até as novas mídias de comunicação. Estas inovações foram analisadas sob o aspecto do risco que estas tecnologias traziam para dentro da sociedade contemporânea. Autores como Ulrich Beck (1986) com sua teoria da sociedade de risco, dominavam o cenário e na base de uma ética para a civilização tecnológica, proposta por Hans Jonas (1979), recomendava-se "precaução". Porém, antes de voltar a essas vozes críticas e as preocupações por elas formuladas, algumas palavras sobre a história do conceito de inovação, essa vez inerente a um entendimento da destruição de estruturas sócio-econômicas tradicionais como sendo criativa.

\section{Inovação enquanto destruição criativa}

Um nome que não pode faltar quando refletimos sobre as origens do conceito de inovação e sua relação com as ciências humanas é de Joseph Alois Schumpeter (1883-1950). Este autor com sua ambígua relação com Marx, ora criticando-o com uma veemência que não deixa pedra sobre pedra, ora apresentando-o como "economista do mais alto nível" (SCHUMPETER, 1947/2005, p. 78) é para muitos autores de hoje a pedra angular de uma teoria da inovação. Schumpeter introduziu, de fato, o conceito de inovação na teoria econômica, através de uma teoria da empresa e do empreendedor dinâmico, desenvolvida em duas abrangentes obras. Por um lado "A teoria do desenvolvimento econômico" de 1912 (Schumpeter, 1912/2006) e por outro na sua última publicação em vida, “Capitalismo, Socialismo e Democracia” de 1942. (Schumpeter, 1947/2005). Schumpeter, depois de ter publicado "0 desenvolvimento econômico" ficou cedo conhecido e reconhecido, mas sofreu mais tarde um evidente ofuscamento por ninguém menos do que John Maynard Keynes. Somente desde os anos 80 começou uma redescoberta de Schumpeter, não por último através da tentativa de ancorar uma teoria da inovação nas ciências econômicas. 
Joseph Schumpeter se opõe a tese da economia clássica de um equilíbrio entre oferta e demanda, o mercado abstrato é para ele somente um tipo ideal, no sentido de Weber. Na realidade existiria um crescimento evolucionário dinâmico, impulsionado por inovações. As inovações ocorrem tanto no nível de novos produtos, métodos produtivos e organizacionais como na abertura de novos mercados e desejos de consumo. A causa imediata da inovação, todavia, é a atividade do empresário individual que, concorrendo com outros, tenta ampliar suas vantagens e seu lucro. A inovação possui uma ambiguidade fatal. Por um lado ela introduz o novo, mais atraente e competitivo, por outro ela elimina empresas que ainda produzem no nível tradicional, oferecendo os produtos de sempre. A criatividade que inova e a destrutividade que elimina o ultrapassado fazem parte do processo de inovação concebido por Schumpeter no já famoso conceito de “destruição criativa” (SCHUMPETER, 1942/2005, p. 134-142).

O capitalismo é por sua natureza uma forma ou um método da mudança econômica e não é e nunca pode ser estacionário (...) O impulso fundamental que coloca e mantém a máquina capitalista em movimento vem dos novos bens de consumo, dos novos métodos de produção e transporte, dos novos mercados e de novas formas da organização industrial, criados pelo empreendimento capitalista. (SCHUMPETER, 1942/2005, p. 136.)

Schumpeter interpreta a história econômica moderna como uma seqüência de invenções, racionalizações e revoluções. Esses mecanismos vem de dentro da estrutura econômica e “... destroem, sem parar, a estrutura antiga e criam permanentemente novas." (SCHUMPETER, 1942/2005, p. 138) As inovações não se realizam sempre com a mesma velocidade. Entre verdadeiras rupturas causadas por ondas de inovações podem acontecer calmarias durante as quais o nível de inovação se generaliza e consolida. Pois, a longo prazo, também este nível tecnológico vai ser questionado, destruído e substituído por outro mais vantajoso, mais atraente e mais eficaz. 
Schumpeter volta-se criticamente contra um entendimento da concorrência baseada exclusivamente na competição dos preços. Para ele existe também uma concorrência da qualidade e da satisfação do consumidor. Na realidade da economia capitalista podemos observar a concorrência através da introdução de uma nova mercadoria, de uma nova tecnologia, de uma nova fonte de energia, ou de um novo tipo de organização. Somente a expectativa que o outro prepare uma inovação já acelera os esforços de cada um para antecipar o que está prestes a surgir: a próxima inovação.

Schumpeter distingue nitidamente entre uma invenção e a sua imposição real. Não é, para ele, uma boa ideia que algo modifica e leva a mudança, mas sua realização, divulgação e imposição. Desenvolvimento gera permanentemente a continuação do próprio desenvolvimento. Curiosamente este pode perpetuar também sem crescimento; um aspecto eventualmente interessante para a economia ecológica do desenvolvimento. Schumpeter, distingue-se do mainstream da economia quando articula sua perspectiva de que desenvolvimento depende exclusivamente de fatores internos à empresa. Modelos de transferência de know how e recursos, que seguem um lógica do input, como uma intervenção do estado na atividade empresarial, são estranhos à essa perspectiva. Desenvolvimento surge no sistema econômico de forma endógena. Sentimo-nos lembrados da sociologia sistêmica de Niklas Luhmann e seus sistemas autopoéticos ou autoorganizacionais (LUHMANN, 1984). Também quando o "ambiente" exterior ao sistema fica constante muda-se este, seguindo seu código específico. No entanto, Schumpeter conhece o empreendedor que funciona como um fator de distúrbio dentro do sistema. Esse destrói o equilíbrio para ativar os mecanismos de inovação. Como Luhmann, Schumpeter possui uma viva consciência da contingência, o que significa: ele sabe que algo é como é, mas também poderia ser diferente. 0 empresário schumpeteriano é, além de ser o centro de energia desenvolvimentista da sua teoria, um agente da contingência. Indeterminação, a per- 
cepção do novo e ruptura é uma tríade formulada por Schumpeter, que caracteriza o desenvolvimento através da inovação. 0 empresário enquanto empreendedor inovador distingue-se do empresário da rotina. 0 empreendedor inovador é um homem de ação, que não se orienta primeiramente nas demandas do mercado, mas tenta convencer o consumidor das vantagens da novidade. Seu negócio é a imposição da boa ideia, a realização de novos caminhos, o desenvolvimento de mercados do futuro. Conhecimento sem sua integração em novas combinações dos fatores de produção permanece economicamente irrelevante. 0 conhecimento, sob essa perspectiva, segue a mesma lógica do dinheiro; ele existe em abundância, mas, somente gera resultados práticos quando vinculado com o processo real de inovação. Schumpeter é um dos primeiros que introduz um aspecto empresarial no debate sobre a sociedade do conhecimento com vastas conseqüências para o debate atual sobre a relação entre universidade e institutos de pesquisa por um lado e a empresa capitalista, pelo outro.

\section{As consequências de inovações tecnológicas e sociolo- gia da técnica}

Desde os anos cinquenta do século XX - e em contraste com o otimismo inovador de Schumpeter antes da Primeira Guerra - concentra-se uma boa parte das publicações e eventos científicos sobre novas tecnologias na questão das instabilidades e riscos provocados por sua introdução em uma sociedade e um ambiente natural não preparados para elas. Essa relação crítica com as inovações técnicas tem, na área das ciências humanas, em especial na filosofia, antropologia e sociologia uma já consolidada tradição. Na verdade houve uma ruptura nas abordagens destes campos do saber na primeira metade do século vinte. Depois de ter compartilhado durante todo século XIX uma filosofia do progresso que festejava o desenvolvimento das forças produtivas e cumprimentava cada invenção, descoberta e evo- 
lução técnica como sinal de um progresso contínuo e inevitável da ciência, a perspectiva muda depois da Primeira Guerra Mundial. Agora, para muitos observadores ganharam as inovações tecnológicas uma face ambígua. A metralhadora tinha mostrado, no campo de batalha, sua eficácia como máquina de matar. Não menos inovadora, uma nova ciência com futuro promissor, a química, contribuiu para o progresso com a composição de um gás letal. 0 aço de primeira linha, sem o qual os arranha céus das novas metrópoles não existiriam, mostrou suas qualidades como material primordial dos navios de guerra, tanques e canhões. E até os primeiros aviões, concebidos por seus construtores para levar o homem para seus destinos de forma mais rápida, perdeu sua inocência nos primeiros combates aéreos na história da humanidade. Dúvidas começaram circular entre os cientistas e mais ainda nas massas populares em contato direto com a "máquina da guerra" e as máquinas das novas linhas de montagem. Sucessos editoriais como a "Decadência do Ocidente" de Oswald Spengler (1918), são um sintoma da mudança de humor dos leitores dessa época. Em 1931 o mesmo autor deveria dedicar um livro inteiro à relação do homem com a técnica e descrever como o criador das máquinas ia se tornar o escravo destas (SPENGLER, 1931).

Sob a evidência da crescente importância da técnica, não somente nesta primeira guerra industrializada, mas também na produção, no transporte, na comunicação, habitação e medicina surge um campo de reflexão que se dedica, dos mais variados ângulos das disciplinas envolvidas, à técnica. Assim, antropólogos como Plessner surpreendem com a tese: "O homem é artificial por natureza." (PLESSNER, 1928). Essa tese, outro antropólogo, Arnold Gehlen, deveria retomar e desenvolver na sua obra mestre: "O homem" (GEHLEN, 1940/1986; GEHLEN, 1957). Aqui Gehlen apresenta o homem como um ser deficitário que compensa a falta de garras com a invenção da faca, a falta de pelos com a produção de tecidos, a falta de asas com a construção do avião e assim adiante. A técnica, entendida em Spengler, como tática de sobrevivência e em Plessner e Gehlen como compensação de 
falhas ou faltas na organicidade do homem, tinha se tornado definitivamente e explicitamente tema das ciências sociais.

Todavia domina, em especial no campo macro-sociológico, uma visão crítica no tratamento do processo da modernização, da crescente racionalização nela embutida e das constantes inovações tecnológicas (ANDERS, 1956). Já Max Weber tinha transformado o determinismo progressista de Marx em seu oposto postulando que o processo da racionalização crescente levaria à uma burocratização inevitável e, em geral, a um estreitamento das possibilidades de escolha do ator social. Weber foi o teórico principal do processo da racionalização interpretado como força motriz da modernização. 0 horizonte dessa inovação racionalizante é negativo, sem alternativa e terminal. "A queima da última tonelada do combustível fóssil", anunciara a inversão da teleologia positiva marxiana. Não surpreende que uma boa parte da sociologia depois da segunda guerra identifica a técnica e a dinâmica por ela desenvolvida com o mundo manipulado e administrado onde uma dialética negativa (ADORNO, 1970) tornaria a emancipação dos assalariados cada vez mais improvável. A sociedade economicamente evoluída ganhou, através da evolução das suas forças produtivas, novos recursos de manipulação como as novas mídias eletrônicas, a indústria do lazer e o consumo em geral; fato que inviabilizou a ação emancipadora do proletariado enquanto "sujeito revolucionário". O homem uni-dimensional (MARCUSE, 1964) e adepto de uma ideologia fornecida curiosamente pela própria ciência e técnica (HABERMAS, 1968/1994) povoava a planície do "capitalismo tardio". Não surpreende que a "teoria crítica" entregue desta maneira à "dialética negativa" encerrou um ciclo de inovações dentro do próprio campo do marxismo e tornou este sem interface (nichtanschlussfähig, Luhmann) para evoluções teóricas posteriores. A tentativa de Jürgen Habermas de abrir as perspectivas fechadas através de uma teoria da ação comunicativa (HABERMAS, 1981) ainda deixa transparecer o veredicto da primeira geração da Escola de Frankfurt sobre a economia e administração modernas: também 
em Habermas estas estavam, enquanto sistemas, entregue a sua própria lógica e avessas aos processos emancipatórios. Somente do "mundo da vida" esperava Habermas ainda discursos, praticas e consensos emancipatórios acerca de uma ética igualitária.

\section{Respostas institucionais aos "impactos" tecnológicos}

Apesar do esgotamento, nos anos setenta, das meta-narrativas sociológicas sobre os rumos da sociedade moderna (LYOTARD, 1979), outras fontes de reflexão sobre a relação entre sociedade e técnica, economia e ambiente e o futuro do desenvolvimento tecnológico foram abertas. Emblemático neste contexto é a publicação, em 1972, de um relatório para o Clube de Roma de um grupo e pesquisadores liderados por Meadows (1978). Este relatório tematizava os limites do crescimento das economias industrializadas sob o aspecto da disponibilidade dos recursos naturais, em especial das fontes de energia fossilizadas como do carvão mineral e do petróleo. Os prognósticos eram sombrios e encontraram ressonância no sistema político. No mesmo ano da publicação do relatório sobre os Limites do Crescimento foi aberto o Office of Technology Assessment pelo congresso dos Estados Unidos. Estamos frente à primeira institucionalização da tentativa de estimar os impactos da introdução de novas tecnologias sobre o meio ambiente e a sociedade. Outras instituições com a mesma tarefa deveriam surgir, assim, em 1986 aparecem no parlamento europeu o Scientific and Tecnological Options Assessment Project e fundações semelhantes no nível dos Estados nacionais, como na Alemanha, em 1990, o Büro für Technikfolgenabschätzung de Deutschen Bundestages - escritório para a avaliação dos impactos das inovações técnicas do parlamento alemão.

Os estudos sobre impactos das inovações tecnológicas se tornaram numerosos e diversificaram seu espectro. Assim surgiram no âmbito das engenharias estudos sobre riscos e propostas de valores-limites, seja de substâncias tóxicas contidas em certos 
produtos, da emissão de ruídos ou de poluentes de máquinas e motores. As pesquisas no âmbito das ciências humanas tematizaram preferencialmente questões éticas e sociais das velhas e novas tecnologias, e sociólogos interessados nas relações entre sociedade e técnica, apresentaram os primeiros estudos empíricos sobre a aceitação ou não das inovações e acerca dos "impactos" sobre as populações "atingidas" (SPINNER, 1989).

Nos últimos anos adicionaram-se aos estudos sobre "impactos" aqueles que buscam saber mais sobre a gênese social da técnica. Como surgem certas linhas do desenvolvimento tecnológico e outras desaparecem e caem no esquecimento? Como é possível fortalecer novas linhas do desenvolvimento menos danosos para ambiente e sociedade? 0 horizonte temporal abriu-se para o futuro, não somente para desenhar cenários apocalípticos que "prognosticam" com meios da extrapolação estatística o que não é prognosticável, mas para incentivar alternativas. No contexto dessa mudança de foco, da observação dos impactos e análise da sócio-gênese das novas tecnologias consolida-se a sociologia da técnica (RAMMERT, 1993). A gênese da técnica e a reflexão sobre os impactos sociais da introdução de técnicas novas são os dois pilares da sociologia da técnica. Num certo sentido ela complementa as ciências tecnológicas tradicionais, as engenharias, revelando como normas, hábitos, aspectos culturais, interesses socioeconômicos entre outros influenciam o desenvolvimento técnico, ampliando desta maneira a visão meramente material, energética, funcional ou informacional da engenharia.

\section{Sociologia circunstancial e a técnica}

Na tentativa de ancorar a sociologia da técnica na episteme consagrada da própria sociologia podemos observar que uma sociologia aberta para incluir artefatos na análise das relações humanas parece mais propícia à fundamentação teórica da sociologia da técnica do que uma sociologia meramente relacio- 
nal. 0 primeiro que nos chama para uma análise das "coisas" é Emile Durkheim, que queria que tratássemos os fatos sociais como tais. Obviamente não pensava nas relações sociais como se fossem objetos materiais, queria somente expressar o caráter coercitivo que exercem sobre o indivíduo e postular sua objetividade. De certa maneira, usando Durkheim como fonte de inspiração, podemos identificar artefatos que, quando inseridos na sociedade, obrigam seu usuário imediatamente para determinado comportamento. Assim, uma rua pode ser interpretada como um dispositivo técnico que exige do motorista seguir as regras do trânsito. 0 próprio automóvel, quando colocado em circulação, permite certas movimentações do seu condutor e exclui outras configurando desta maneira a relação que o motorista tem com outros motoristas e pedestres. Outros meios de transporte como o avião são, a tal ponto, uma reunião de prescrições sociais que não funcionariam sem um comportamento direcionado e disciplinado, tanto da sua crew como dos passageiros comuns. Essa perspectiva sociológica parece frutífera, além das análises da esfera de circulação e do trânsito, em especial quando analisamos o ambiente urbano, regiões industrializadas ou qualquer milieu social nas sociedades modernas que envolve artefatos (LINDE, 1972; HALBWACHS, 1986; JOERGES, 1989). Seria igualmente interessante refletir de que maneira dispositivos técnicos participam na erupção de certos distúrbios psicológicos como ansiedade, estresse, claustrofobia ou síndrome de pânico; distúrbios que são, como mostra a clínica psiquiátrica, frequentemente vinculados aos elevadores, aeronaves, engarrafamentos e outros arranjos sócio-técnicos vividos pelo paciente como hostis e "detonadores" do seu desequilíbrio emocional. De qualquer maneira ganham as circunstâncias técnicas, com o avanço do processo da modernização, cada vez mais relevância para a compreensão de fenômenos sociais. Assim, a análise da "maquinaria" está no centro da teoria da exploração de Marx que atribui a ela um papel chave no processo do aumento da mais-valia relativa. Além do mais, torna-se o homem, nessa perspectiva analítica circunstancial, de tal maneira dependente do 
ritmo e das exigências das máquinas que pode ser visto como seu "apêndice". 0 trabalho morto, nas palavras de Marx, começa dominar o trabalho vivo. A teoria da reificação e da alienação contida na sociologia de trabalho de Marx faz referências diretas à importância de objetos, coisas, instrumentos, máquinas e processos técnicos. Numa curiosa definição do seu conceito de capital escreve Marx “(...) o capital não é uma coisa, mas uma relação social intermediada por coisas” (MARX, 1972, p. 793). Exatamente a intermediação de relações sociais por coisas é hoje tema da sociologia da técnica, que quer saber como relações sociais modificam-se através da técnica e de qual maneira técnicas são "cristalizações" de relações sociais, i.e. sócio-técnicas. Tanto Durkheim como Marx, com suas sociologias circunstanciais, oferecem interfaces pra evoluções teóricas posteriores, assim autores como Popitz (1957), Habakuk (1962), Ribeiro (1968), Bell (1973), Rosenberg (1976), Leroi-Gourhan (1980), Moscovici (1982), discutem, sem ser necessariamente adeptos de Marx, suas teses sobre a relação entre homem e máquina no contexto da teorização do desenvolvimento histórico da sociedade.

Uma discussão sobre Max Weber e sua relação com a sociologia da técnica é um caso à parte. Pois sua opção por uma interpretação da ação social através da "compreensão" do sentido visado pelo ator individual, dá a sua perspectiva sociológica, primeiramente, um cunho claramente relacional. Também a técnica é, para Weber, em primeiro lugar ação: técnica de orar, técnica de ascese, técnica de administrar e assim adiante. No decorrer da explanação da sua sociologia ganham, todavia, as grandes unidades (o estado racional com sua burocracia, p.e.) e os grandes processos (entre eles o mais importante a racionalização) supremacia sobre o ator individual. Para este resta a gaiola de ferro, por sua vez uma metáfora que coloca a estrutura reificada sobre a liberdade do agir individual. A ordem moderna baseada no estado racional, na empresa capitalista e na tecno-ciência, avançando sobre todas as alternativas históricas tradicionais com um dinâmica racionalizante e globalizante, engole o ator social, 
seu sentido visado e, assim nos parece, o objetivo inicial do individualismo metodológico de Weber. Este, como muitos outros autores, começa com um detalhe, neste caso o ator e seu sentido visado, para nos deixar uma análise das grandes dinâmicas e estruturas. Sua sociologia do agir desemboca numa sociologia da ordem social e a inovação racionalizante com fortes traços negativos (DAWE, 1978).

\section{Ética e técnica: o problema da fundamentação e da comunicação}

Contrariando a teleologia negativa e racionalizante de Weber, a conceituação schumpeteriana de inovação parece não conhecer direção e critério senão a vitória e o sucesso do empresário no mercado. A destruição criativa não contempla o que foi destruído e não submete a criação do novo a uma restrição ética. Exatamente essa autodelimitação foi exigida por Hans Jonas e toda uma corrente subsequente de autores que queriam submeter a pesquisa e principalmente o desenvolvimento de novas tecnologias a uma ética para a civilização tecnológica (JONAS, 1979). Antes, já nos anos cinquenta, alertava o filósofo Martin Heidegger para o perigo que a técnica moderna trazia para a sociedade humana, não chegou, todavia, a formulação explícita de uma ética, como seu discípulo Jonas. Heidegger, anti-metafísico par excelence, sabia da dificuldade de fundamentar uma ética fora do campo metafísico e a ontologia por ele apresentada em Ser e Tempo (HEIDEGGER, 1927) trouxe somente algumas poucas e fracas opções valorativas. 0 que fazer com o discurso da autenticidade no campo do agir e mais precisamente da técnica? A primeira metade da obra de Heidegger parece, e ainda isso dizemos com bastante cautela, nas suas conseqüências mais perto de alguma forma de decisionismo (veja o dúbio conceito de Entschlossenheit) do que preparar um posicionamento ético. Mais tarde, quando desenvolve uma filosofia da técnica (HEIDEGGER, 1953) propriamente dita, procuramos igualmente sem sucesso 
uma ética com ela vinculada. Heidegger deixa para seus leitores e interpretes a tarefa de descer ao nível da práxis social, que sem valores, normas, prescrições e moral nem existiria. Assim Bruno Foltz tenta derivar dos escassos comentários de Heidegger sobre o "morar" e o "construir" uma ética ambiental, supostamente contida na obra do filósofo (FOLTZ, 1995). Uma "ética da finitude" detectada por Loparic (1994), possui, além de angariar a simpatia do leitor, pouca operacionalidade e omite a resposta que esperamos da ética à pergunta: o que devo fazer, em especial no campo das inovações tecnológicas? Com Heidegger, assim parece, estamos condenados à uma posição de contemplação, permanecendo imóveis na beira do abismo, lugar para o qual a técnica moderna nos conduziu.

Uma simples ética (proibitiva) referente à dinâmica das inovações tecnológicas parece lutar com dois problemas principais. O primeiro é o da sua fundamentação não-metafísica, o que a condena a se tornar alguma forma de consenso condensado legalmente, então, sem força de uma prescrição ética divina e exposta à erosão por processos comunicativos. E o segundo é seu caráter inibidor e bloqueador de processos de inovação cujos resultados, por natureza, não podemos antecipar. Ética e técnica parecem incomunicáveis, problema que Niklas Luhmann explicita de forma original (LUHMANN, 1988 e 1992). Em situações como estas, quando a reflexão parece estar presa num beco sem saída temos, todavia, opções. Uma é: ignorar o problema e desenvolver um discurso, um "vocabulário final”, diria Rorty, que, também sem “fundamento", pode convencer (RORTY, 1992).

\section{Inovação enquanto design das coisas}

0 que chamamos antigamente de design se refere em geral à uma modelagem estética de um objeto, seja este um automóvel ou o interior de uma casa, para dar a este objeto uma forma que vai além da sua mera função, todavia respeitando a funcionali- 
dade nas suas propostas. Design durante muito tempo foi um adicional, mera forma, sob ponto de vista funcional no fundo desnecessário e considerado de menor importância enquanto disciplina técnica ou artística em comparação com as engenharias.

Não obstante, assistimos nos últimos tempos uma extensão contínua do significado da palavra design que deixou de se referir exclusivamente e somente à superfície de produtos fabricados. Cidades, paisagens, parques e hotéis possuem hoje um design; igualmente corpos e rostos, movimentos e atitudes e brinquedos eletrônicos de última geração. 0 design, além do mais, deixou de ocupar somente a superfície das coisas, ao ponto que é difícil dizer, pensando nos iphones e tablets por exemplo, onde termina o seu design e onde começa a sua mera função enquanto máquina de comunicação. 0 design penetrou as coisas e parece estar a caminho de engendrar a própria natureza. O DNA de muitos seres vivos não exige ser redesenhado? 0 nosso corpo não chama para ser melhorado e remodelado?

Com Bruno Latour podemos distinguir cinco características deste novo entendimento de design (LATOUR, 2009). 0 primeiro refere-se à uma, por assim dizer, modéstia deste conceito. Em comparação com a palavra construir ou edificar o design parece expressar um agir muito mais fraco. Quando construo um objeto me coloco radicalmente na posição de seu autor, quando faço o design de algo, respeito a sua existência prévia, reconfiguro algo e não o descaracterizo totalmente. Segundo, o design tem um compromisso com o detail, não se trata mais de fabricar algo apressadamente. 0 design integra um certo cuidado na produção e expressa uma sensibilidade artística pelas qualidades das coisas. A terceira conotação do design é a sua crescente absorção de significados. Para Galilei, já o livro da natureza era escrito em conceitos matemáticos e assim podia ser lido. Hoje, com a penetração de artefatos digitalizados no nosso cotidiano, amplia-se dramaticamente a necessidade de uma hermenêutica dos significados das coisas, já que estas se tornaram, no sentido de Hei- 
degger, uma reunião de símbolos e signos. A leitura adequada dos significados das coisas abre a possibilidade de reescrever parte das suas mensagens, de redesenhar cuidadosamente seu perfil. Quarto, design nunca é uma criação a partir do zero. Design é sempre um redesign. E por último, o design contêm uma dimensão ética, na medida em que podemos falar de um design bom e de um design ruim. Atribuindo às coisas "desenhadas" uma dimensão normativa coloca estas no âmbito da política; a partir de agora, nenhum político pode mais apoiar-se nas coisas como elas são ou como foram feitas. Entendendo a produção de energia elétrica, p.e., como resultado de um design, deixa transparecer que materialidade e moralidade formaram uma unidade e assim são passíveis a um redesign. Neste momento não surpreende mais tanto que, para Bruno Latour, o conceito de design substitui os antigos conceitos de modernização ou até de revolução. Podemos concluir que até o conceito de inovação pode ser substituído, pelo conceito do design, com a vantagem de fornecer critérios diferenciados do seu uso.

\section{0 novo da inovação}

O que é o novo da inovação? A primeira vista essa pergunta parece não fazer sentido. Tentamos então primeiro uma aproximação através da definição da palavra inovação. Podemos denominar como inovação todos os artefatos, processos e fenômenos que observadores percebem como novo e como melhoria do estado atual (BRAUN-THÜRMANN, 2005). Pois, essa definição, apesar de estar correta, elimina do surgimento da novidade importantes aspectos. Por um lado existem inovações que nem todos os observadores percebem como melhoria. Assim, registramos na história levantes de populações inteiras, como os levantes dos tecelões da Silésia, no início do século XIX, contra a introdução de novas máquinas que inovaram, para não dizer revolucionaram, a produção de tecidos. 0 critério da melhoria percebida pelo observador pode então ser relativizado. Uma 
inovação pode nos conduzir a um estado pior do que o atual? Essa pergunta radicaliza a questão na medida em que exclui o observador e sua subjetividade, que, por ventura, pode ser um elemento retrógrado que não percebe o que realmente acontece. Pois, o novo que a inovação almeja tira toda sua força da imprevisibilidade do seu surgimento. Sabemos que nem sempre as nossas intenções alcançam seus objetivos. Existem efeitos colaterais desconhecidos de novidades farmacêuticas. Existem tiros que saem pela culatra.

Nas últimas décadas, foram muitos os autores que chamaram atenção para a não-determinação plena de processos sociais, econômicos e até materiais e tecnológicos. Sobre ambivalência falavam uns, outros sobre não-linearidade e sobre a ausência de leis históricas que garantiriam um progresso contínuo. Todo esse debate parece culminar naquilo que podemos chamar: a descoberta da contingência. Essa palavra, no linguajar cotidiano erroneamente empregada para falar sobre o acaso, quer nos dizer: algo é necessariamente como é, mas também poderia ser diferente. 0 olhar contingente percebe o novo, que pode surgir de combinações inusitadas e percebe, eventualmente, as forças destrutivas da própria inovação. Equidistante de um determinismo modernizante a qualquer custo, e de um relativismo total dos sentidos, precisa a consciência da contingência encontrar seu lugar na tentativa da realização de um design novo; não somente de processos produtivos, mas de todo um interior deste nosso mundo.

E para sublinhar a leveza deste design, dizemos: às vezes um novo olhar sobre as coisas conhecidas já é uma inovação.

\section{Redesign do desenvolvimento}

A ideia de inovação schumpeteriana parece entregar o desenvolvimento econômico às possibilidades a princípio ilimitadas do empresário e a imprevisibilidade das suas conseqüências. Destruir e 
criar! Eis aí o lema da sua ação. 0 apelo a ruptura inovadora, útil e refrescante em circunstâncias que paralisam a sociedade e a economia, carece, todavia, de um direcionamento capaz de criar um ordenamento macro-sociológico novo e superior ao estado anterior. Não surpreende, sob este aspecto, que Schumpeter, apesar de estar sempre citado quando se trata de destacar a importância da inovação radical, recai no seu livro "Capitalismo, Socialismo e Democracia" (SCHUMPETER, 1947/2005) na defesa da velha ideologia socialista. Mais uma vez fecha-se, também para este autor, o futuro sob signo da ordem teórica. Ela é somente teórica porque a contingência penetra o jogo complexo entre economia, sociedade e natureza a tal ponto que condena a previsão sobre sua trajetória ao reino da especulação, nutrida ou por desejos "sociais" mais diversos, anseios de salvação ou fantasias apocalípticas.

É possível pensar na técnica e seu futuro sem se render a uma crítica abstrata, fornecida pelo discurso ético? Sem se deixar convencer por prognósticos de uma ou outra versão da gaiola de ferro? Sem se deixar levar por uma requentada filosofia do progresso, com a inovação tecnológica no seu centro? Difícil, no ocidente, com suas raízes nas expectativas salvacionistas moldadas pelas tradições judaico-cristãs, é a despedida de qualquer pensamento escatológico, também quando este se apresenta de uma forma radicalmente laicizada. 0 prognóstico do colapso total da sociedade humana é, nesta perspectiva, somente a inversão deste pensamento profundamente cristão. Inúmeras teorias sociais da grande ordem, sejam elas representadas pelo mundo administrado (Horkheimer, Adorno), pela gaiola de ferro (Weber), pela sociedade sem classes (Marx), pelos sistemas (Parsons, Luhmann), pela funcionalidade orgânica das suas partes (Durkheim) ou alguma forma de harmonia entre o social e o natural (Rousseau, Capra) são exatamente isso: teorias da grande ordem - ora combatida, ora almejada.

Parece-nos inútil tentar superar a mais profunda crítica da ordem vigente, se nos é permitido supor por um momento que ela 
de fato existe, ou elaborar o mais perfeito desenho da ordem ideal. As meta-narrativas teóricas podem ainda despertar saudades e curiosidades, não obstante, como herdeiras (inconscientes) do pensamento metafísico estão esgotadas e sua força inovadora está perdida. Somente aquém da grande teoria temos a chance, assim nos parece, de descobrir novidades ou enxergar o antigo de forma diferente. Revisitar, e seja isto somente enquanto exercício da nossa imaginação como inventores e inovadores, aquilo que existia enquanto techné antes dos tempos modernos, pode eventualmente dar pistas para um redesign do dispositivo técnico contemporâneo. Redescobrir o momento estético da antiga técnica diminui, por ventura, a terrível tensão entre as inovações tecnológicas e as exigências éticas contemporâneas. 0 veredito moral e politicamente ineficaz não pode freqüentemente ser substituído pela nítida impressão de que algo se tornou simplesmente feio? Com mais leveza do que a ética, a estética julga as coisas, os homens e seus arranjos. 0 cosumidor, alvo da estética da sedução mercantil, já julga nos seus atos de compra os produtos. A demanda tem um inquestionável poder sobre a oferta. Não somente o empreendedor pode criar e destruir, também seu freguês pode ignorá-lo ou querer outros produtos. A inovação pode começar na mente do consumidor, assim como a crítica pode se renovar na estética de um novo design.

\section{Referências bibliográficas}

ADORNO, Th. W. (1970) Negative Dialektik. Frankfurt am Main: Suhrkamp.

ADORNO, Th.W.; Horkheimer, M. (1971) Dialektik der Aufklärung. Frankfurt: Fischer

ANSERS, Günter (1956) Die Antiquiertheit des Menschen. München: Beck

BAUMAN, Zygmunt $(1991,1999)$ Modernidade e Ambivalência. Rio de Janeiro: Jorge Zahar Editor

BECH, Ulrich. (1986), Risikogesellschaft. Frankfurt, Suhrkamp 
BRAUN-THÜRMANN, Holger (2005) Innovation. Bielefeld: Transcript Verlag BRÜSEKE, Franz Josef (1991) Chaos und Ordnung im Prozess der Industrialisierung. Münster, Hamburg, New York: Lit

BRÜSEKE, Franz Josef (2011) A Modernidade Técnica. Florianópolis: Insular DAWE, Alan. Teorias de Ação Social. In: Bottomore, Nisbet (orgs.). História da Análise Sociológica. Rio de Janeiro: Zahar, pp.475-546. (1978) 1980

DURKHEIM, Emile (1984) A divisão do trabalho social, 2 vls., Lisboa: Editorial Presença.

DURKHEIM, Emile (1989) As formas elementares da vida religiosa. São Paulo: Paulinas.

FOLTZ, B.V. Habitar a Terra. Heidegger, Ética Ambiental e a Metafísica da Natureza. Lisboa: Instituto Piaget, 1995

FREUD, Sigmund (1963) Das Unbehagen in der Kultur, in: ibd. Gesammelte Werke XIV, Frankfurt am Main, pp.477

GEHLEN, Arnold (1957) A alma na era da técnica. Lisboa: Livros do Brasil GEHLEN, Arnold. (1940/1986) Der Mensch. Seine Natur und seine Stellung in der Welt. Wiesbaden: Aula Verlag.

HABERMAS, Jürgen (1968/1994) Técnica e Ciência como Ideologia. Lisboa: Edições 70

HABERMAS, Jürgen (1981) Theorie des kommunikativen Handelns. 2 vols., Frankfurt: Suhrkamp

HEIDEGGER, Martin. (1997), "A questão da técnica” ["Die Frage nach der Technik"]. Cadernos de Tradução , 2: 40-93, São Paulo, USP, Departamento de Filosofia

HEIDEGGER, Martin. Ser e tempo. Petrópolis: Vozes, (1927) 1990

HORKHEIMER, Max (1937) Traditionelle und Kritische Theorie. In: Max Horkheimer. Kritische Theorie, Vol. 1, p.137-191, Frankfurt 1968: Fischer

JONAS, H. (1979/1984) Das Prinzip Verantwortung. Versuch einer Ethik für de technologische Zivilisation. Frankfurt: Suhrkamp

LATOUR, Bruno (2009) Ein vorsichtiger Prometheus. In: Jongen, Tuinen, Hemelsoet, orgs. Die Vermessung des Ungeheuren. Philosophie nach Peter Sloterdijk. Paderborn: Wilhelm Fink, p.357-375

LOPARIC, Z. (1994) "Ética e Finitude". In: NUNES, B. (org.) A Crise do Pensamento. Belém: Editora da UFPa. 1994, p. 37-122 
LUHMANN, Niklas (1984) Soziale Systeme. Frankfurt: Suhrkamp LUHMANN, Niklas (1988/1990) Ökologische Kommunikation - Kann die moderne Gesellschaft sich auf ökologische Gefährdungen einstellen? Opladen: Westdeutscher Verlag.

LUHMANN,Niklas (1992a) A improbabilidade da comunicacão. Vega passagens.

LUHMANN,Niklas (1997) Die Gesellschaft der Gesellschaft. Frankfurt: Suhrkamp

LUHMANN,Niklas. (1991), Soziologie des Risikos. Berlim/Nova York, Walter de Gruyter

LYOTARD, J.F. (1979/1990) O Pós-Moderno. Rio de Janeiro: José Olympio

MAFFESOLI, Michel. (2001 [1997]), Sobre o nomadismo: vagabundagens pós-modernas. Rio de Janeiro, Record

MARCUSE, Herbert (1964) The one-dimensional man. Boston: Beacon Press MARX, K. (1972a) Das Kapital, 1.vol.; in: Marx Engels Werke, vl. 23 (= MEW 23); Berlin: Dietz Verlag;

MARX, K. (1972b) Das Kapital, 3.vol.; in: Marx Engels Werke, vl. 25 (= MEW 25); Berlin: Dietz Verlag;

MEADOWS, Dennis L., MEADOWS, Donella H., RANDERS, Jörgen, BEHRENS, William W. (1972) Limites do Crescimento - Um Relatório para o Projeto do Clube de Roma sobre o Dilema da Humanidade. São Paulo: Editora Perspectiva

PARSONS, Talcott (1937) The Structure of Social Action, Glencoe: Free Press PARSONS, Talcott (1951) The Social System, New York: Free Press

PLESSNER, Helmut (1928) Die Stufen des Organischen und der Mensch. Einleitung in die philosophische Anthropologie.

RAMMERT, Werner (1993) Technik aus soziologischer Perspektive. Opladen: Westdeutscher Verlag

RORTY, Richard. (1992 [1989]), Contingência, ironia e solidariedade. Lisboa, Editorial Presença

SCHUMPETER, Joseph (1912/2006) Theorie der wirtschaftlichen Entwicklung. Berlin: Duncker \& Humblot

SCHUMPETER, Joseph (1942/2005) Kapitalismus, Sozialismus und Demokratie. Tübingen: Narr Francke Attempto Verlag 
SLOTERDJK, Peter (1983) Kritik der zynischen Vernunft. Frankfurt: Suhrkamp

SPENGLER, Oswald (1918/1997) Der Untergang des Abendlandes. München: Beck

SPENGLER, Oswald (1931/1993) 0 homem e a técnica. Lisboa: Guimarães Editores.

Spinner XXX

WEBER, Max (1985) A ética protestante e o espírito do capitalismo; São Paulo: Livraria Pioneira Editora

WEBER, Max (1991) Economia e Sociedade: Fundamentos da Sociologia Compreensiva. 2 vols. Brasília: Editora Universidade de Brasília.

Data de Recebimento: 19 de dezembro de 2014

Data de Aprovação: 30 de dezembro de 2014 